INSA Policy Statement

\title{
A Policy Statement on "Dissemination and Evaluation of Research Output in India" by the Indian National Science Academy (New Delhi)
}

PRAVEEN CHADDAH ${ }^{1, *}$ and SUBHASH C LAKHOTIA ${ }^{2, *}$

${ }^{1}$ Flat 702, Block 24, Heritage City, Gurgaon 122 002, India

${ }^{2}$ Cytogenetics Lab, Department of Zoology, Banaras Hindu University, Varanasi 221 005, India

(Received on 14 May 2018; Accepted on 15 May 2018)

\begin{abstract}
Considering the necessity of common and objective parameters of assessment of research outputs, the Indian National Science Academy (New Delhi) has, after extensive deliberations involving its entire fellowship, issued this policy statement on Dissemination and Evaluation of Research Output in India. It is expected that this will be adopted and implemented by different agencies/regulatory bodies in India.
\end{abstract}

\section{Executive Summary}

\section{Introduction}

Research adds to human knowledge by addressing well-posed questions about the unknown. Science progresses only when a new discovery is subjected to thorough peer-review and further validated by the community. Since similar and over-lapping questions in a given knowledge domain would be bothering many, an element of competition has resulted in scientists wanting to quickly disseminate their results. Research output is also 'owned' by the disseminating researchers, as implied by the fact that research papers are not published without author names. The increasing numbers of authors and, therefore, increasing competition, technological advances in the methods of dissemination of information and the inevitable geo-political biases have had a great impact on the research output dissemination process, which is largely in the form of research journals. Developments on the internet in recent decades have allowed dissemination of research findings without delay and with a much higher potential for better visibility than before.

Translational research, our ability to attract young generation to participate in intellectually challenging research as a way of life, and finally the prestige of the country's research community, are largely dependent on the 'basic' research carried out in country. Therefore, development of appropriate criteria for assessment of basic research is very important. In the absence of well thought out policies, mediocrity prevails. One such example is the alarming rise of predatory journals and predatory conferences in the country and elsewhere.

The perceived importance of the research output is used in the evaluations of an author's and/or an institution's research contributions. While research leading to patents can be assessed on the basis of exploitation of the patent by industry etc., an objective assessment of basic research presents many challenges.

\section{Need for a Consistent Policy on Dissemination and Evaluation of Research Output in India}

The research output from India has increased remarkably in recent decades, thanks to increasing investments in, and expectations from, R\&D activities. This has also led to increased demands on methods to assess the quality and quantity of research output of an individual and/or institution. Besides the serious limitations of the

*Authors for Correspondence: E-mail: chaddah.praveen@gmail.com and lakhotia@bhu.ac.in 
various bibliometric parameters used for the diverse assessments, the methodologies and parameters applied by different agencies in the country also show significant inconsistencies. Inappropriate guidelines about assessment by different agencies and their misuse have seriously vitiated the research output and assessment scenario in the country. Therefore, it is necessary to develop common policies that promote healthy practices for dissemination and evaluation of research output in the country.

This document discusses and recommends basic policy parameters about the following issues: i) Promotion of a pre-print archive publication policy, ii) Promoting journals published in India, iii) Minimizing predatory journals and predatory conferences in the country, iv) Policies for categorizing and evaluating research efforts, and v) Policies for payment of 'open access' charges and publication of conference proceedings, specifically in Indian context.

\section{Preprint Repositories and Peer Review after Dissemination}

Preprints archives provide 'gold open-access' for sharing un-peer-reviewed manuscripts with scholarly community in the given field prior to formal publication. Such platforms, providing eternal 'gold-open-access', ensure not only the claim for priority, but also facilitate informed feedback from a large number of peers which can be helpful in preparing articles for formal publication. The current common practice of listing submitted or in preparation manuscripts in grant applications/nominations for awards etc, permits the assessors neither to learn about the actual contents of the manuscript nor to access peer reactions, and thus precludes an objective evaluation. Open accessibility of manuscripts on Pre-print Archives facilitates their objective assessment.

\section{Recommendation}

3.1. Various agencies/organizations in India that fund research should take cognizance of articles that have been deposited in established free open access Pre-Print Archives as a proof of prior-data. However, for further evaluation of author's contributions for assessment etc., peer-reviewed publication is important.

\section{Promoting Journals Published in India}

In order to improve the ranking of research carried out in India, there is an urgent need to have good international recognition of research/review journals published in India. This requires appropriate encouragement to our academic community to also submit their quality research papers to journals published in India, especially those that are published by established academies, societies etc, have long standing history of publication and follow good policies and practices of peer-review and publication process.

\section{Recommendations}

4.1. No agency should ask separate listing of research publications in 'National' and 'International Journals'.

4.2. It is essential to take steps to enhance the visibility of established Indian journals by proactively encouraging researchers in the country to publish some of their papers in these journals.

4.3. Papers published in established Indian journals may even be given special attention during any assessment if their citation significantly exceeds the average citation rate of the journal.

\section{5. 'Publish or Perish' Policy, Open Access Charges and Evolution of So-Called Predatory Journals}

The increasing use of scientometric parameters for assessing individual's research contributions and institutionalized norms for certain minimal numbers of publications to be mandatory for eligibility for faculty appointment/promotion etc have fuelled the rush to publish. This has been exploited by unscrupulous business interests resulting in mushrooming of 'predatory journals' and 'predatory conferences'. Such sub-standard journals and conferences 
need to be positively discouraged.

\section{Recommendations}

5.1. The academic community, especially the young research scholars and faculty need to be sensitized about predatory journals and conferences so that they do not fall prey to such un-academic activities.

5.2. Funding agencies should advise the concerned investigators to refrain from publication/participation in predatory and substandard journals (i.e., those that started publishing only as online journals in recent past, levy open-access or other charges, assure rapid publication and have ambiguous peer-review process and publication policies) and conferences. Such publications and participations must not be counted as research output.

5.3. Funding agencies and institutions should not generally provide funds to the conference organizers for independent publication of the proceedings of a conference/seminar unless the conference is meant to be a brainstorming to review the status of a field and to plan future directions.

5.4. Payment of open access charges, except in case of publication in well established journals of repute, may be generally avoided

5.5. Articles placed on established pre-print archives, which provide perpetually free access to all, should be encouraged.

5.6. Emphasis has to be on quality rather than quantity.

\section{Criteria for Evaluating Research Output: "What Did You Publish" Rather Than "Where Did You Publish?"}

The inevitable assessment and evaluation of research output of an individual or an institution over a period of time has entailed a large variety of scientometric or bibliometric parameters. Despite the serious questions about the journal impact factor and other similar metrics by academic bodies across the world, such measures continue to be formally used in India leading to unhealthy competition and assessment.

\section{Recommendations}

6.1. Assessment of an individual's research contributions should primarily be based on the impact of what is published rather than on where it is published. The 'impact factor' of a journal must not be used as the primary indicator nor should it be used in isolation.

6.2. Instead of assessing on numbers of papers published by an individual, assessors should find out if the research output was only confirmatory in nature or led to incremental or path-breaking advances.

6.3. Each of the 'best 5' papers identified by candidate/nominator should be categorized as 'confirmatory', 'incremental advance' or 'path-breaking advance'. Identification of a work as 'path-breaking advance' should be justified by (a) explicit citations from non-overlapping authors or (b) brief statement as to why the applicant/nominator considers the given work as 'path-breaking'.

6.4. In cases of multi-authored papers, specific contribution by the applicant/nominee in the given paper should be clearly identified for assessment.

It is believed that the above suggested policies on dissemination and evaluation of our research output would promote quality basic research and help develop scientific temper in the country. 


\section{Introduction}

Research adds to human knowledge by addressing well-posed questions about the unknown. Since similar and over-lapping questions in a given knowledge domain would be bothering many, an element of competition in finding answers often becomes an essential component of research. The need for a quick dissemination of the research output is thus a natural consequence of this competitive profession. Research output is also 'owned' by the disseminating researchers, as implied by the fact that research papers are not published without author names! The perceived importance of the research output is, therefore, used in the evaluations of an author's research contributions.

The increasing numbers of authors and, therefore, increasing competition, technological advances in the methods of dissemination of information and the inevitable geo-political biases have had a great impact on the research output dissemination process, which is largely in the form of research journals. Developments on the internet in recent decades have allowed dissemination of research findings without delay and with a much higher potential for better visibility than before.

A widely accepted and followed principle requires that any claim of a new knowledge addition should be independently verifiable. Dissemination is a prerequisite for wider validation. However, current models also require some validation prior to the actual dissemination of new findings to the community. The practice of review by peers prior to wider dissemination, in vogue for a few centuries, serves to ensure the scientific soundness of the research output being reported. There is an increasing debate in recent times (see HCSTC, 2011; Baldwin, 2017) regarding possible bias in favour of papers submitted from established institutes, and about reviewers being biased towards established ideas and thus stifling innovation. This has raised serious concerns about the current system of pre-dissemination or pre-publication peer review being really objective enough to provide a rational validation. The pre-publication peer-review does not necessarily ensure a rational and complete validation because, besides the above concerns, errors in the manuscript may be missed by the limited number (typically 1 to 4 ) of experts who see the manuscript. The increasing number of manuscripts being submitted to increasing numbers of journals limits the availability of reviewers and often those who become available are not able to or willing to provide the required time and effort. Even fraudulent data have been published in the most respected journals. Such attempts are usually due to one or the other kind of material benefits to researchers that follow their publication. There have been reports (Woolston, 2014) that journals with higher perceived prestige value also have higher retraction rates! This has been attributed, on the negative side, to authors being less honest and cutting corners to get a publication in such prestigious journals. On the positive side, this has also been attributed to higher visibility of the given journal resulting in a higher level of scrutiny. Such retractions of published papers are examples of post-dissemination (or postpublication) review at work. It follows that dissemination without delay but with a high level of visibility ensures both (i) ownership of the researchers and (ii) a proper post-dissemination validation and evaluation of the research output. Validation of major path-breaking research output has always been linked to the post-publication acceptance by the community of researchers in the field, and not just to its being published in any journal, however 'reputed' it may be.

Developments on the internet in recent decades have allowed dissemination of research findings without delay and with a much higher potential for better visibility than before. Researchers now access the contents page of new issue of a journal, scroll to search titles of interest, and then read them at appropriate levels of detail. Old issues are accessed through a specific search process, or through a hyperlink to a particular paper in a more recently published paper. Accessing soft copies provides features that were not available with hard copies, e.g., one can magnify graphs or figures for detailed features, one can focus on particular portions of a paper through a search for an appropriate keyword, one can read a cited paper by clicking on a hyperlink, the easily portable pdf files can be used for discussions with others by adding comments or highlighting key portions, etc. The online availability of a pdf file of the published work has thus become the preferred mode for a much wider dissemination of research output. The easy availability and the perceived conveniences of reading a soft copy is rapidly resulting in extinction of hard copies. As discussed later, the 
multiple conveniences of the availability of soft copies of published work on internet have also entailed several serious concerns.

Publishers have also been influenced by developments in the internet. The online submission of a manuscript makes it instantaneously available to editor and reviewers. The practice of 'ahead of print' online publication, increasingly followed by publishers, has enhanced the speed with which readers can read and comment upon the findings and thus influence the impact of new findings. In some cases, this has also resulted in corrections being incorporated in the final version after the corrected proofs were available online. Although a post-publication review has always existed, the internet has made it an effective alternative to the usual pre-publication peer review (HCSTC, 2011).

\section{Need for a Consistent Policy on Dissemination and Evaluation of Research Output in India}

Translational research, our ability to attract young generation to participate in intellectually challenging research as a way of life, and finally the prestige of the country's research community, are largely dependent on the 'basic' research carried out in country. The perceived importance of the research output is used in the evaluations of an author's and/or an institution's research contributions. While research leading to patents can be assessed on the basis of exploitation of the patent by industry etc, an objective assessment of basic research presents many challenges. Therefore, development of appropriate criteria for assessment of basic research is very important. In the absence of well thought out policies, mediocrity prevails. One such example is the alarming rise of predatory journals and predatory conferences in India and elsewhere.

Research output from India has increased remarkably in recent decades, thanks to increasing investments in, and expectations from, R\&D activities (Pohit et al., 2015). This has obviously led to increased demand on methods to assess the quality and quantity of research output of an individual and/or institution.

A variety of bibliometric parameters like the Journal Impact Factor, Citation Index, H-index etc have been widely used in India. Several recent reports (Lakhotia, 2010; Chaddah, 2014a, 2015; Noone, 2016;
Bornmann and Marx, 2016; Elango and Ho, 2017; van Leeuwen and Wouters, 2017) have discussed the limitations and even undesirability of application of most of these parameters for assessment purposes. Besides the limitations of the various bibliometric parameters being used for the diverse assessments, the methodologies and parameters used by different agencies in the country show significant inconsistencies. Inappropriate guidelines about assessment by different agencies and their misuse have also seriously vitiated the research output scenario in the country. Notwithstanding the fact that no method of assessment can be completely free of subjective judgments, it is necessary that these issues are discussed to develop policies that promote healthy practices for dissemination and evaluation of research output in the country.

This document discusses and recommends basic policy parameters about the following issues: i) Promotion of a pre-print archive publication policy, ii) Promoting journals published in India, iii) Minimizing predatory journals and predatory conferences in the country, iv) Policies for categorizing and evaluating research efforts, and v) Policies for payment of 'open access' charges and publication of conference proceedings, specifically in Indian context. It is believed that these recommendations would be helpful to the growth of quality research in the country and elsewhere.

\section{Preprint Repositories and Peer Review After Dissemination}

Preprints are un-peer-reviewed manuscripts which authors use to share their current results to the scholarly community in their field prior to formal publication so that they can not only claim priority, but also get informed feedback from a large number of peers that is expected to be helpful in revising and preparing articles for submission to a journal for formal publication. Preprint archives provide a platform for permanently storing soft copies of such manuscripts with open access to any interested person. In this 'gold open-access' mode of dissemination, neither the author nor the reader is charged. Even prior to the internet, some specialist groups did circulate preprints as an extension of a seminar to an audience that could not be physically present. For example, the High- $\mathrm{T}_{\mathrm{C}}$ Newsletter used to be delivered by post and contained 
titles of preprints, with commentaries on some of them. With the advent of internet, one of the first and popular online preprint archives was 'arXiv' (http://arXiv.org) which in over 25 years of its existence, strongly influenced many publishers and impacted how science is disseminated (Nature Physics Editorial, 2016). Some of the currently available preprint archives in different branches of sciences are: $\operatorname{arXiv}$ (http://arXiv.org) for physics, mathematics, computer science, quantitative biology, quantitative finance, statistics; bioRxiv (bioRxiv.org, Cold Spring Harbor Laboratory) for biological sciences; Therapoid Preprint (https:// therapoid.net/ by Open Therapeutics) for biomedical sciences; and ChemArxiv (chemArxiv.org, by the American Chemical Society) for Chemistry.

These pre-print archives ensure that the submitted manuscripts become available freely within a working day of being uploaded, subject to some essential and sensible restrictions. These archived preprints are also citable like any other published paper. Once uploaded on these established pre-print archives, the manuscript cannot be withdrawn: they remain on the internet for ever. This feature ensures selfimposition of quality because reputations are at stake. The pre-print repositories allow modifications, with all the versions remaining freely available for perpetuity. When the pre-print manuscript or its modified version gets published in a formal journal, author/s can add a note on the archived pre-print that provides link to the published paper. They can then provide open-access manuscript versions of papers published in journals that are 'reader-funded'. These pre-print archives also provide diverse metrics that go beyond those provided by any journal, which foreshadow the future evolution of bibliometric parameters.

Preprint archives offer several advantages to authors because of which they are being taken seriously not only by authors but by funding agencies as well. As discussed earlier (Chaddah, 2011, 2012, 2013, 2014a, 2016a; Nature Physics Editorial, 2016), there are multiple benefits of uploading on a preprint archive, especially for researchers from developing countries. Preprint archiving enables immediate selfdissemination and helps establishing priority and counters idea-plagiarism. More importantly, such uploads enable researchers to bypass any bias that referees may have against new bylines. It is a common experience that in the process of ensuring publication, authors, especially the young and less established researchers from developing countries, often dilute/ modify their conclusions as they succumb to subtle or less than subtle pressure exerted by reviewers/editors against their new ideas that question the commonly held view/s. Uploading on a preprint archive ensures an open-access record of authors' original conclusions/interpretations. Preprint archiving also provides opportunities for feedback as in a seminar but from a much wider audience. All these points are succinctly summed up in a recent NIH (2017) note "Scientists issue preprints to speed dissemination, establish priority, obtain feedback, and offset publication bias". Establishing priority is essential for countering idea-plagiarism. This is an unethical practice in which established and other researchers, who can assess the value of out-of-the-box ideas, especially from emerging bylines, paraphrase and publish them as their own and get regular citations (Chaddah, 2014b). Unfortunately while the IPR Cells in the country are focusing on establishing priority for patentable research, little concern is visible on the part of different authorities about the need for protecting the ownership of ideas also. Preprint archives provide a mechanism for claiming ownership of ideas.

The current common practice of listing submitted or in preparation manuscripts in grant applications/ nominations for awards etc, does not permit the assessors to learn about contents of the manuscript, have no peer reactions available to assessors, and thus preclude an objective evaluation. Open accessibility of manuscripts on Pre-print Archives, on the other hand, facilitates their objective assessment.

\section{Recommendation}

3.1. Various agencies/organizations in India that fund research should take cognizance of articles that have been deposited in established free open access Pre-Print Archives as a proof of prior-data. However, for further evaluation of author's contributions for assessment etc., peerreviewed publication is important.

\section{Promoting Journals Published in India}

One of the major concerns of Prof. C V Raman was 
that unless the country has its own high quality research journals, the quality of science in the country would not be high. Due to initiatives taken by scientists of yesteryears, a large number of research journals are being published, uninterrupted over decades, in India. Unfortunately, most agencies that fund, recruit or reward, ask the applicants to provide separate lists of publications in 'National' and 'International Journals' (Lakhotia, 2013). An implied outcome of such distinction is that papers published in the 'national' journals are poorer than those in 'international' journals. Such unjustified implication has resulted in most of the so-called 'national journals' being trapped in the vicious circle of submission of poor quality manuscripts by the community and consequent low recognition and citations and therefore low-impact factor (Lakhotia, 1990, 2013, 2014), although it is also true that in times of strong competition, many have resorted to Indian journals. Most of the traditional Indian journals do not charge from authors, and provide free full-text access on the internet. It is essential to take steps to enhance the visibility of these journals by proactively encouraging established researchers to publish some of their papers in journals, especially those that are published by established academies, societies etc.

Papers published in established Indian journals may even be given special attention during any assessment if their citation significantly exceeds the average citation rate of the journal.

\section{Recommendations}

4.1. No agency should ask separate listing of research publications in 'National' and 'International Journals'.

4.2. It is essential to take steps to enhance the visibility of established Indian journals by proactively encouraging researchers in the country to regularly publish some of their research outputs and other articles in these journals as well.

4.3. Papers published in established Indian journals may even be given special attention during any assessment if their citation significantly exceeds the average citation rate of the journal.

\section{5. 'Publish or Perish' Policy, Open Access Charges and Evolution of the So-called Predatory Journals}

The advent of internet and very fast growth of the world-wide web has transformed research publication process. Publishing has become faster and easier. At the same time the volume of research papers being published has become very large, thanks to the rapidly increasing number of researchers and increased demands on them to publish or perish. Consequently, research publication has become an industry with enormous commercial interests. Contrary to the expectation that spread of internet and replacement of hard-copy journals by the online soft copy versions would make the dissemination of research outputs less expensive and thus benefit a wider audience, the ever-increasing subscription costs have resulted in the earlier practice of 'reader pays for reading a paper' to 'author pays for being read' model. The 'open access charge' that the author or his/her institution or the supporting agency is required to pay in this model is not trivial so that even for a reasonably funded researcher in India, it can be a substantial drain on the grants available for research. Generally, higher the rating/prestige of a journal, higher is the open access charge that the author needs to pay. Apparently the profit margins are very high (Lakhotia, 2017). Even professional learned societies use profits from publications for other academic and professional activities.

The increasing use of scientometric parameters for assessing individual's research contributions and institutionalized norms for certain minimal numbers of publications to be mandatory for eligibility (e.g., the current UGC regulations for minimum standards for $\mathrm{Ph}$.D. or faculty appointment/promotion etc.) have fuelled the rush to publish. Unscrupulous business interests have exploited this situation resulting, especially during the past decade, in mushrooming of the so-called 'predatory journals' (Beall, 2012; Lakhotia, 2015, 2017a, 2017b, Patwardhan et al., 2015; Clark and Thompson, 2016; Jayaraman, 2017) which publish anything for a fee. Since prestigious journals often charge hefty amounts (can be as high as a few lakh Indian Rupees) per accepted openaccess paper, there is plenty of 'room at the bottom' for the other publishers to exploit the needy and gullible authors. These publishers cannot be wished away; 
they wreck havoc with our existing evaluation system and must be contained and countered by evolving our evaluation system. India, unfortunately, is one of the leading countries in publication of such journals, thanks to some mis-guided and ill-implemented policies (Priyadarshini, 2017).

The DBT and DST Open Access Policy seeks open-access for all publications resulting from their funding, but recognizes that the authors are restricted by time-embargoes that are imposed by many foreign publishers even on manuscript versions. The efficacy and popularity of the repositories created under this Policy needs to be enhanced (Chaddah, 2016b). It may be noted in this context that most journals published by academies and established academic societies in India are fully open-access, without any charge to authors or readers, and thus impose no restrictions on their archiving on open repositories.

Parallel to the worrying scourge of predatory journals, there has been a rapid and widespread emergence of "predatory conferences" (Lakhotia, 2015, 2017a; Cobey et al., 2017), which like the predatory journals, only help the 'predator' organizer to earn money from the 'prey', who 'earns' the required points to fulfill/improve the minimal 'academic performance index' (API) score defined by the University Grants Commission, New Delhi. Those who register for such predatory conferences are also assured of 'publication of paper in UGC-approved Journals' or as a chapter in conference proceedings based e-book with ISBN, besides 'Presentation \& Publication certificates'. Such fraudulent exercises have no academic merit and yet help the person meet certain UGC norms, which ironically were put in place to promote quality academic activities.

Even some traditional conferences that have been regularly held since many years, have recently started publishing Proceedings through reputed publishers who charge a hefty amount, and put in a note that papers have been reviewed by the conference organizers. Such conference proceedings are hardly cited, but preclude submission of the work to standard journals. Thus not only the new knowledge fails to be properly disseminated but remains susceptible to possible plagiarism (Chaddah, 2016a). Such journals and conferences need to be positively discouraged.

\section{Recommendations}

5.1. The academic community, especially the young research scholars and faculty need to be sensitized about predatory/substandard journals and conferences so that they do not fall prey to such un-academic activities.

5.2. Funding agencies should advise the concerned investigators to refrain from publication/participation in predatory and substandard journals (i.e., those that started publishing only as online journals in recent past, levy open-access or other charges, assure rapid publication and have ambiguous peer-review process and publication policies) and conferences. Such publications and participations must not be counted as research output.

5.3. Funding agencies and institutions should not generally provide funds to the conference organizers for independent publication of the proceedings of a conference/seminar unless the conference is meant to be a brainstorming to review status of the field and to plan future directions.

5.4. Payment of open access charges, except in case of publication in well established journals of repute, may be generally avoided.

5.5. Articles placed on established pre-print archives, which provide perpetually free access to all, should be encouraged.

5.6. Emphasis has to be on quality rather than quantity.

\section{Criteria for Evaluating Research Output: "What Did You Publish" Rather Than "Where Did You Publish?"}

Assessment and evaluation of research output of an individual or an institution over a period of time is inevitable in the current competitive world. A large variety of methods and metrics have been developed leading to emergence of new disciplines like Scientometrics or Bibliometrics. Each of the methods and metrics that have been advocated has its own limitations and associated controversies. Despite the fact that the journal impact factor has been seriously 
questioned by academic bodies across the world (Lakhotia, 2009, 2013, 2014; Johnston, 2013; Jacobs, 2014, Callaway, 2016; Kiesslich et al., 2016), this measure continues to be formally used in India, as evident from the fact that most assessment forms/ nomination forms, ask for IF of the journals where the research has been published.

Research output of an individual and/or institution has to be evaluated by the impact it makes. The first measure of the impact is how many people read the paper. The metric giving the number of downloads is made available by many journals; the pre-print archives also provide this metric. This metric is generally not used as a measure for evaluation because the download is anonymous with no hint of the reaction on reading. This metric can, nevertheless, provide some indication of readers' interest in the paper. The other measure of impact is if the paper is relevant enough to be cited. This metric (Citation index) is currently used for evaluating a paper. It is also used for evaluating a researcher; either directly through the citation index or through h-index, both of which have their own limitations and associated controversies (Chaddah, 2014a). Another measure of impact of a paper is if it changes the research of other researchers, it would be cited/discussed extensively and/ or multiple times in a paper by non-overlapping authors. This metric is presently not generally available, but would be easy to be made available.

The evaluation process must distinguish between 'confirmatory' research and research that leads to 'incremental' or 'path-breaking' advance. The citation profile vs time is different for different levels of 'novelty' (Stephan et al., 2017). This is obvious because in most cases, out-of-the-box novel ideas take time to be accepted. The time-profile of citations, a metric that is readily available, can be used in conjunction with the frequency with which the paper is cited in papers of non-overlapping authors.

While evaluating a researcher, we also need to look at the body of work. The work could be of the 'hit-and-run' variety, with few papers on many different topics. Or it could have concentrated on a few problems, which could have even created new directions and/or keywords. In this case papers by non-overlapping authors would cite many papers of the same author/s. 'How many papers of an author are cited in one paper of non-overlapping authors?' is thus another relevant metric.

While evaluating the research output of a researcher (as also of an institution), we need to move away from 'where did you publish' to 'what did you publish' so that instead of calculating the journal's impact factor, we actually look at what is published and what impact it had or may have on other researchers.

\section{Recommendations}

6.1. Assessment of an individual's research contributions should primarily be based on the impact of what is published rather than on where it is published. The 'impact factor' of a journal must not be used as the primary indicator nor should it be used in isolation. Information about Impact Factor of the journal where a paper is published should not be asked for.

6.2. Instead of assessing on numbers of papers published by an individual, assessors should find out if the research output was only confirmatory in nature or led to incremental or path-breaking advances.

6.3. Each of the 'best 5' papers identified by candidate/nominator should be categorized as 'confirmatory', 'incremental advance' or 'path-breaking advance'. Identification of a work as 'path-breaking advance' should be justified by (a) explicit citations from nonoverlapping authors or (b) brief statement as to why the applicant/nominator considers the given work as 'path-breaking'.

6.4. In cases of multi-authored papers, specific contribution by the applicant/nominee in the given paper should be clearly identified for assessment.

\section{Concluding Remarks}

This document has covered two aspects viz. dissemination of research output, and evaluation of research output. Dissemination is necessary for validation, a pre-requisite for the output to be accepted as an addition to human knowledge. Dissemination must also ensure ownership of the output, and prevent 
its being plagiarized before this ownership is accepted and registered. Assessment of the quality of new knowledge created through research is not a straight forward process and no single method can become error-proof. The most important and essential component is that the assessors understand the nature

\section{References}

Baldwin M (2017) In referees we trust? Physics Today 70 44-49

Beall J (2012) Predatory publishers are corrupting open access Nature $\mathbf{4 8 9} 179$

Bornmann, L and Marx W (2016) The journal impact factor and alternative metrics EMBO Reports 17 1094-1097

Callaway E (2016) Publishing elite turns against impact factor Nature $\mathbf{5 3 5}$ 210-211

Chaddah P (2011) E-print archives ensure credit for original ideas Sci Dev net Oct 17 http://www.scidev.net/global/ communication/opinion/e-print-archives-ensure-credit-fororiginal-ideas.html

Chaddah P (2012) Ensuring credit for original thought Current Science $\mathbf{1 0 3} 350$

Chaddah P (2013) Knowledge creation from our universities Current Science $\mathbf{1 0 5} 566$

Chaddah P (2014a) Improving scientific research, even without changing our bureaucracy Current Science 106 1337-1338

Chaddah P (2014b) Not all plagiarism requires a retraction Nature 511127

Chaddah P (2015) Lessons on impact factor from the DBT and DST open access policy Proc Indian Natn Sci Acad $\mathbf{8 1}$ 553-555

Chaddah P (2016a) On the need for a National Preprint Repository Proc Indian Natn Sci Acad 82 1167-1170

Chaddah P (2016b) Enhancing the efficacy of the 'DBT and DST Open Access Policy' Current Science 110 294-295

Clark A M and Thompson D R (2016) Five (bad) reasons to publish your research in predatory journals $J$ Adv Nurs $\mathbf{7 3}$ 2499-2501 doi:10.1111/jan.13090

Cobey K D, de Costa e Silva M, Mazzarello S, Stober C, Hutton B Moher D and Clemons M (2017) Is this conference for real? Navigating presumed predatory conference invitations J Oncology Practice 13 410-413 doi 10.1200/JOP. 2017.021469

Elango B and Ho Y S (2017) A bibliometric analysis of highly and significance of the contributions, rather than rely on empirically defined scientometric parameters. It is expected that the present recommendations would provide for objective assessment and thus be helpful to the growth of quality research in the country and elsewhere.

cited papers from India in Science Citation Index Expanded Current Science 1121653

HCSTC (House of Commons Science and Technology Committee) (2011) Peer review in scientific publications. Report no. HC 856 https://www.publications.parliament.uk/pa/ cm201012/cmselect/cmsctech/856/856.pdf

Jacobs H (2014) Something rotten EMBO Reports 15817

Jayaraman K S (2017) UGC rules blamed for helping promote fake journals in India Nature India http://www. natureasia.com/en/nindia/article/10.1038/nindia.2017.114 doi:10.1038/nindia.2017.114

Johnston M (2013) We have met the enemy, and it is us Genetics 194 791-792

Kiesslich T, Weineck S B and Koelblinger D (2016) Reasons for journal impact factor changes: influence of changing source items PloS One 11 e0154199

Lakhotia S C (1990) Poor science, poor journals Current Science 59 773-774

Lakhotia S C (2009) Nature of methods in science: technology driven science versus science driven technology Bioessays 31 1370-1371

Lakhotia S C (2010) Impact factor' and 'we also ran' syndrome Current Science $\mathbf{9 9} 411$

Lakhotia S C (2013) 'National' versus 'International' Journals Current Science 105 287-288

Lakhotia S C (2014) Why we publish, what we publish and where we publish? Proc Indian Natn Sci Acad 80 511-512

Lakhotia S C (2014) Research, Communication and Impact (Editorial) Proc Indian Natn Sci Acad 80 1-3

Lakhotia S C (2017a) The fraud of open access publishing Proc Indian Natn Sci Acad 83 33-36

Lakhotia S C (2017b) Mis-conceived and mis-implemented academic assessment rules underlie the scourge of predatory journals and conferences Proc Indian Natn Sci Acad 83 513-515

Marcus A and Oransky I (2015) What's behind big science 
frauds? New York Times May 222015

Nature Physics Editorial (2016) Keep posting Nature Physics 12 719

NIH (2017) Reporting preprints and other interim research products https://grants.nih.gov/grants/guide/notice-files/ NOT-OD-17-050.html

Noone K J (2016) Beware the impact factor Ambio 45 513-515

Patwardhan B, Dhavale D D, Bhargava S, Deshpande R, Jaaware A, Ghaskadbi S and More M (2015) Guidelines for Research Publications http://www.unipune.ac.in/uop_files/ Report-Guidelines_20-5-15.pdf

Pohit S, Mehta K and Banerjee P (Editorial Coordination) (2015) India: Science and Technology, Vol. 3. Foundation Books, Cambridge University Press (New Delhi) and CSIR-
National Institute of Science,Technology and Developmental Studies (New Delhi)

Priyadarshini S (2017) India tops submissions in predatory journals Nature India http://www.natureasia.com/en/nindia/ article/10.1038/nindia.2017.115 doi:10.1038/nindia. 2017.115

Stephan P, Veugelers R and Wang J (2017) Reviewers are blinkered by bibliometrics Nature 544 411-412

van Leeuwen T N and Wouters P F (2017) Analysis of publications on Journal Impact Factor over time Frontiers in Research Metrics and Analytics 24 doi.org/10.3389/ frma.2017.00004

Woolston C (2014) High retraction rates raise eyebrows Nature 513283. 